\title{
Biotypes of Klebsiella pneumoniae (sensu lato) and Enterobacter aerogenes characterised by differential substrate metabolism: application of the technique
}

\author{
J. G. BARR AND G. M. HOGG \\ From the Department of Clinical Bacteriology, Royal Victoria Hospital, Belfast, Northern Ireland, UK
}

SUMMARY A biochemical typing method is described for Klebsiella pneumoniae (sensu lato) and Enterobacter aerogenes. The technique depends on differences in metabolism of five carbon substrates-glycerol, inositol, lactose, glucose, and xylose-at two concentrations. Reproducibility is satisfactory and is monitored by the incorporation of control klebsiellae of known biotype.

The method has been used for 12 months in the surveillance of urinary tract colonisation in this hospital. Gut carriage of klebsiellae, implicated by several workers as a source of infection, was common among staff and new admissions. Many biotypes were represented which were sensitive to most antibiotics except ampicillin.

Klebsiellae, all multiply resistant, were isolated most frequently from urine specimens in two orthopaedic wards. In a longitudinal study in these wards, a sequential dominance in urinary tract colonisation by two klebsiella biotypes was shown, which suggested the presence of cross infection or an environmental reservoir. Confirmatory evidence was obtained from capsular serotypes and R-factor studies.

Klebsiellae are one of the major causes of hospital acquired infection. This has led to the development of many methods which aimed to detect identical strains of the same species and thus provide a reliable method for epidemiological studies.

Serological (Casewell, 1972; Riser et al., 1976; Palfreyman,1978), biochemical (Rennie and Duncan, 1974; De Silva and Rubin, 1977), and bacteriocine typing methods (Ślopek and Maresz-Babczyszyn, 1967; Heddell and Mitchell, 1978) have been developed for Klebsiella spp. with varying degrees of success. Less attention has been given to Enterobacter spp.

Of the methods available for the typing of klebsiella strains, serological typing, by Quelling reaction, indirect immunofluorescence, or counter immunoelectrophoresis, has gained the widest acceptance. Biochemical typing or bacteriocine typing alone has often failed to be sufficiently discriminating, and the value of biochemical typing has been questioned by De Silva and Rubin (1977), who suggested that multiple biotypes occurred commonly in single clinical specimens.

Received for publication 7 March 1979
Biochemical typing, however, if feasible, would be quick and inexpensive and could overcome the requirements for special reagents and special expertise often needed by other methods. Barr (1978) identified a number of biochemical test substrates whose differential metabolism provided good discrimination between isolates of klebsiella. In our experience, differential metabolism of these substrates also allowed discrimination between isolates of Enterobacter aerogenes. The various biotypes of Klebsiella pneumoniae (sensu lato) and Enterobacter aerogenes distinguished by the differential metabolism of five selected substrates are described here.

This technique is applied to surveillance of biochemical types of klebsiella associated with colonisation of the urinary tract. The results suggest that the preponderance of certain biotypes in some wards could be attributed to cross infection or to a common source.

\section{Material and methods}

ORGANISMS: ISOLATION AND IDENTIFICATION A total of 445 clinical isolates of klebsiellae were examined over a 12-month period. These included 
322 isolates of $K$. pneumoniae (sensu lato) and 123 isolates of $E$. aerogenes. The vast majority $(91 \%)$ were isolated from urine; the remainder were isolated from a variety of specimens including faeces, sputa, and wounds.

Those strains examined were primarily selected by their capacity for rapid aesculin hydrolysis (Aesculin bile agar, Difco). Isolates were identified on the basis of aesculin hydrolysis, citrate utilisation, ornithine decarboxylation, phenylalanine deamination, indole production, $\mathrm{H}_{2} \mathrm{~S}$ production, colony colour on xylose lysine decarboxylase agar, urease production, and motility; biochemical tests were carried out as described by Barr et al. (1977).

Strains presumptively identified as Klebsiella spp. were further biochemically typed by the methods proposed for Klebsiella spp. by Rennie and Duncan (1974). The same biochemical tests were also carried out with isolates of $E$. aerogenes. Differentiation of klebsiella biotypes (Rennie and Duncan, 1974) was on the basis of three groups of test results: group $\mathrm{A}$-indole production, Voges-Proskauer test, and citrate utilisation; group B-lactose and sucrose fermentation, malonate and gluconate utilisation; group C - dulcitol fermentation, lysine and ornithine decarboxylation, and urease activity. Different reaction sequences in each group were identified by single-digit codes, and the biotypes were recorded from the three biochemical test groups as three-digit codes.

\section{MEDIA}

Cultures were maintained on nutrient agar slopes and streaked on MacConkey agar 24 hours before use. Media for the identification of clinical isolates were prepared as described by Barr et al. (1977). Media for the biotyping of clinical isolates by the methods of Rennie and Duncan (1974) were prepared, and biochemical tests carried out, by conventional methods (Cowan, 1974).

In order to facilitate detection of multiple biotypes in urine, urine sediment was streaked on MacConkey agar and on five minimal media, each containing one of the substrates used in discrimination between strains by differential substrate metabolism. The minimal media contained (g/l); $\mathrm{K}_{2} \mathrm{HPO}_{4}, 7 \cdot 0$; $\mathrm{KH}_{2} \mathrm{PO}_{4}, 30 ;\left(\mathrm{NH}_{4}\right)_{2} \mathrm{SO}_{4}, 1.0 ; \mathrm{MgSO}_{4}, 7 \mathrm{H}_{2} \mathrm{O}, 0 \cdot 1$; $\mathrm{NaCl}, 5.0$; neutral red agar, 15.0; and either glycerol, inositol, lactose, glucose or xylose, 5.0.

Biotyping of klebsiella and enterobacter isolates by differential substrate metabolism was carried out in Andrade's peptone water (Oxoid: Batch 062

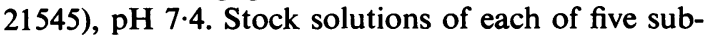
strates (glycerol, inositol, lactose, glucose, and xylose) at each of two required concentrations $(0.3 \%$ and $0.2 \%$ for inositol, lactose, glucose, and xylose; $0.6 \%$ and $0.4 \%$ for glycerol) were prepared by the addition of filter-sterilised solutions of the appropriate substrate. Stock solutions in peptone water were stored for not more than three months at $4^{\circ} \mathrm{C}$.

Selection plates for the detection of resistance transfer were prepared by the addition of filtersterilised antibiotic solutions to autoclaved media as follows:

MacConkey agar + rifampicin $(75 \mu \mathrm{g} / \mathrm{ml})+$ tetracycline $(15 \mu \mathrm{g} / \mathrm{ml})$

MacConkey agar + rifampicin $(75 \mu \mathrm{g} / \mathrm{ml})+$ kanamycin $(20 \mu \mathrm{g} / \mathrm{ml})$

MacConkey agar + rifampicin $(75 \mu \mathrm{g} / \mathrm{ml})+$ carbenicillin $(25 \mu \mathrm{g} / \mathrm{ml})$

MacConkey agar + rifampicin $(75 \mu \mathrm{g} / \mathrm{ml})+$ ampicillin $(25 \mu \mathrm{g} / \mathrm{ml})$

MacConkey agar + rifampicin $(75 \mu \mathrm{g} / \mathrm{ml})+$ streptomycin $(20 \mu \mathrm{g} / \mathrm{ml})$

ISO sensitest agar + rifampicin $(75 \mu \mathrm{g} / \mathrm{ml})+$ sulphamethoxazole $(100 \mu \mathrm{g} / \mathrm{ml})$

DETECTION OF MULTIPLE BIOTYPES IN URINE Urine sediment was streaked on to MacConkey's medium and the minimal media described above. Where differences in colonial form, or medium indicator colour change associated with colonies, were observed, representative colonies were selected and purified for further testing. Six colonies were selected from the final streak. Where no differences could be detected among colonies on one plate, six colonies were selected at random.

All colonies selected were identified by the methods described.

ISOLATION OF KLEBSIELLAE FROM FAECES

Faeces were plated directly on aesculin bile agar (Difco), Simmon's citrate agar (Difco), and MacConkey agar (with lactose replaced by inositol). Faeces were also incubated for $\mathbf{4 8}$ hours in citrate broth and MacConkey broth (with lactose replaced by inositol) and then plated on the three primary isolation media described above. Isolates, selected on the basis of reactions on these media, were identified by the methods described.

\section{ANTIBIOTIC SENSITIVITY TESTING}

Antibiotic sensitivity was determined using discs (Oxoid) with control strains of Staphylococcus aureus NCTC 6571 and Escherichia coli NCTC 10418. Tests were carried out on Diagnostic Sensitivity test agar (Oxoid) with $10 \%$ lysed blood. Sensitivity or resistance to the following antibiotics was determined: tetracycline, trimethoprim, sulphamethoxazole, ampicillin, carbenicillin, kanamycin, 
gentamicin, cephalosporin, nitrofurantoin, naladixic acid, and mecillinam.

R-PLASMID STUDIES

Twenty multiply resistant klebsiella strains isolated from two orthopaedic wards $(41 / 42)$ were tested for their ability to transfer their antibiotic resistance to a rifampicin-resistant recipient strain of $E$. coli $\mathrm{K} 12$.

Donor and recipient strains were incubated at $37^{\circ} \mathrm{C}$ for 16 hours in nutrient broth (Oxoid); $0.5 \mathrm{ml}$ of donor culture and $1 \mathrm{ml}$ of recipient culture were added to $9 \mathrm{ml}$ fresh nutrient broth and incubated at $37^{\circ} \mathrm{C}$ for 16 hours. Volumes of $0.1 \mathrm{ml}$ were then spread over selection plates (see Media) and incubated at $37^{\circ} \mathrm{C}$. Growth on selection plates was streaked out to obtain single isolated colonies, and antibiotic resistance or sensitivity was determined by the disc method described above.

\section{BIOTYPING TECHNIQUE}

Biotyping of klebsiella and enterobacter isolates was achieved by comparing strain variation in the metabolism of five substrates (xylose, glucose, lactose, inositol, and glycerol), each at two concentrations.

Comparisons of substrate metabolism were carried out in microtest plates (M24ART, Sterilin). Medium $(50 \mu \mathrm{l})$ was distributed in each well using a minipipetter (Cooke microtitre system; Dynatech Laboratories Ltd). Medium was distributed in the following order: xylose, glucose, lactose, inositol, and glycerol in peptone water. For each substrate the lower concentration was dispensed first and the dispenser was thoroughly rinsed out between substrates with Andrade's peptone water without substrate addition. Bacterial suspensions were prepared in peptone water by transferring single colonies from 18-hour cultures on MacConkey agar. Inoculum suspensions were incubated for 4 hours at $37^{\circ} \mathrm{C}$ and dispensed in a microtest plate (M24 ARTL; Sterilin) which served as a template. Normally 32 inoculum suspensions were dispensed in triplicate to give three blocks of 32 strains (four rows of eight strains) in each template.

Inocula were transferred from the template to test plates using a 96-pin multipoint inoculator (Denley Instruments Ltd). Test plates were inoculated in order (xylose, glucose, lactose, inositol, and glycerol) with the lower concentration of each substrate inoculated first. Inoculated microtest plates, without lids, were placed inside sterile antibiotic assay plates (Luckham Ltd) with the base lined with filter paper (Whatman 41; Whatman Lab. Sales) and moistened with $50 \mathrm{ml}$ of water. Two microtest plates, representing the two concentrations of each test substrate, were placed within each antibiotic assay plate in a central position. Each antibiotic assay plate was placed centrally on a separate shelf of a jacketed incubator (Laboratory Thermal Equipment) humidified by $500 \mathrm{ml}$ water placed in the bottom of the incubator.

Test plates were incubated at $37^{\circ} \mathrm{C}$ for 22 hours.

\section{RECORDING OF TEST RESULTS}

Tests of substrate metabolism at each concentration were recorded as positive $(+)$ or negative $(-)$ according to the presence or absence of an indicator colour change resulting from acid production. For each substrate, at two concentrations, three possible results were therefore possible: test results positive at both concentrations, denoted ' 2 '; test results positive only at higher concentration, ' 1 '; and test results negative at both concentrations, ' 0 '. This yields for each strain a five-digit code indicative of metabolism of two concentrations of the five substrates used and recorded in the order glycerol, inositol, lactose, glucose, and xylose, for example, 10221. Since three possible test results could be recorded for each of the five substrates a maximum number of $3^{5}$ or 243 biotypes could be recorded for both klebsiella and enterobacter in the absence of weak intermediate test reactions. Where weak indicator colour changes occurred these were specifically recorded as weak test results (w); this was treated primarily as a negative result, and secondly as positive, such that two five-digit numerical biotypes were recorded for strains yielding an intermediate result in one test reaction. Where more than one intermediate result was recorded for one strain this could result in the recording of additional alternative biotypes. Thus a strain recorded as $11111 / 11221$ yields a positive test reaction only at the higher concentration of each substrate, but also shows a weak reaction at the lower concentrations of lactose and glucose.

\section{Results}

COMPARISON OF BIOCHEMICAL TYPING METHODS

Biochemical typing of klebsiella isolates by the methods of Rennie and Duncan (1974) yielded 24 distinguishable types. Of these, five biotypes accounted for $87 \%$ of the strains examined (Table 1). However, within each of those biotypes identified by conventional methods, many additional biotypes could be distinguished on the basis of differential substrate metabolism. No particular association of biotypes distinguished by differential substrate metabolism could be attributed to any one biotype distinguished by conventional biochemical tests; 
Table 1 Incidence of klebsiella biotypes distinguished by differential substrate metabolism within five major conventional biotypes (Rennie and Duncan, 1974)

\begin{tabular}{lccc}
\hline Conventional biotypes* & $\%$ Incidence among clinical isolates & \multicolumn{2}{c}{ Biotypes (differential substrate metabolism) $\dagger$} \\
\cline { 2 - 4 } & & Number & Dominant types \\
\hline 112 & 40 & 35 & $11222,01112,00111,00222$ \\
111 & 16 & 28 & $11222,00111,00222,11111$ \\
114 & 15 & 10 & 11222 \\
113 & 8 & 11 & 11222 \\
511 & 8 & 00222,11222 &
\end{tabular}

* Biotype 112 was characterised by absence of indole production, a positive Voges-Proskauer reaction, and citrate utilisation (group A reactions); lactose and sucrose fermentation, malonate, and gluconate utilisation (group B reactions); and by absence of dulcitol fermentation, lysine decarboxylation, absence of ornithine decarboxylation, and urea hydrolysis (group $\mathrm{C}$ reactions).

Other biotypes differed from 112 in the following respects: biotype 111 (fermentation of dulcitol); biotype 114 (absence of urea hydrolysis); biotype 113 (fermentation of dulcitol and absence of urea hydrolysis); biotype 511 (indole production and absence of urea hydrolysis).

$\nmid$ Biotypes were distinguished by differences in strain metabolism of five substrates, each at two concentrations (see Material and methods).

thus these two methods could complement one another.

Clinical isolates of E. aerogenes were also examined by the biochemical tests utilised by Rennie and Duncan (1974). The population was very homogeneous, and few biotypes could be identified. Differences did occur in inositol fermentation (cf, Barr and Mahood, 1976), indole production, and malonate utilisation, which could usefully complement strain discrimination on the basis of differential substrate metabolism.
BIOCHEMICAL TYPING BY DIFFERENTIAL

\section{SUBSTRATE METABOLISM}

On the basis of well-defined results alone, a possible total of 243 biotypes could theoretically be distinguished for both $K$. pneumoniae (sensu lato) and $E$. aerogenes. However, the occurrence of weak reactions clearly increases the potential number of biotypes. Such intermediate results were normally reproducible, could allow additional biotypes to be distinguished, and were shown to be independent of variation in the biotyping technique. Thus a biotype

Table 2 Characteristics of 20 major biotypes of Klebsiella pneumoniae (sensu lato) distinguished by differential metabolism of five substrates at two concentrations: percentage incidence among clinical isolates

\begin{tabular}{|c|c|c|c|c|c|c|c|c|c|c|c|}
\hline \multicolumn{10}{|c|}{ Substrate metabolism ${ }^{*}$ at two concentrations $(\% w / v)$} & \multirow[t]{3}{*}{ Biotype $†$} & \multirow{3}{*}{$\begin{array}{l}\% \text { Incidence among clinical } \\
\text { isolates }\end{array}$} \\
\hline \multicolumn{2}{|c|}{ Glycerol } & \multicolumn{2}{|c|}{ Inositol } & \multicolumn{2}{|c|}{ Lactose } & \multicolumn{2}{|c|}{ Glucose } & \multicolumn{2}{|c|}{ Xylose } & & \\
\hline 0.6 & 0.4 & $0 \cdot 3$ & $0 \cdot 2$ & $0 \cdot 3$ & $0 \cdot 2$ & $0 \cdot 3$ & $0 \cdot 2$ & $0 \cdot 3$ & $0 \cdot 2$ & & \\
\hline+ & + & + & + & + & + & + & + & + & + & 22222 & 1 \\
\hline+ & + & - & - & + & + & + & + & + & + & 20222 & 3 \\
\hline+ & + & - & - & + & + & + & + & + & - & 20221 & 1 \\
\hline+ & - & + & + & + & + & + & + & + & + & 12222 & 2 \\
\hline+ & - & + & - & + & + & + & + & + & + & 11222 & 14 \\
\hline+ & w & + & $w$ & + & + & + & + & + & + & $11222 / 22222$ & 1 \\
\hline+ & - & + & - & + & + & + & + & + & - & 11221 & 2 \\
\hline+ & - & - & - & + & + & + & + & + & + & 10222 & 3 \\
\hline+ & - & - & - & + & + & + & + & + & + & 10221 & 2 \\
\hline+ & - & + & - & + & - & + & - & + & - & 11111 & 7 \\
\hline+ & - & - & - & + & - & + & - & + & - & 10111 & 2 \\
\hline+ & - & $\mathbf{w}$ & - & + & - & + & - & + & - & $10111 / 11111$ & 1 \\
\hline+ & - & - & - & - & - & - & - & - & - & 10000 & 1 \\
\hline- & - & + & - & + & - & + & - & + & + & 01112 & 4 \\
\hline- & - & + & - & + & - & + & - & + & - & 01111 & 3 \\
\hline $\mathbf{w}$ & - & + & - & + & - & + & - & + & - & $01111 / 11111$ & 1 \\
\hline- & - & - & - & + & + & + & + & + & + & 00222 & 8 \\
\hline - & - & - & - & + & - & + & - & + & + & 00112 & 8 \\
\hline- & - & - & - & + & - & + & - & + & + & $00112 / 00222$ & 2 \\
\hline- & - & - & - & + & - & + & - & + & - & 00111 & 7 \\
\hline
\end{tabular}

*Substrate metabolism was recorded as positive $(+)$, indicator colour change in Andrade's peptone water with added substrate; negative ( -$)$, no indicator colour change; or weak $(w)$ in the presence of very weak indicator colour change.

$\dagger$ Biotype was derived as described in Material and methods. Each digit of biotype refers to the metabolism of each substrate in order: glycerol, inositol, lactose, glucose, and xylose. In each case, a positive result at both concentrations of a substrate was recorded as ' 2 '; a positive result at the higher substrate concentration only as ' 1 '; and a negative result at both substrate concentrations as ' 0 '. 
Table 3 Characteristics of biotypes of Enterobacter aerogenes distinguished by differential metabolism of five substrates at two concentrations; percentage incidence among clinical isolates

\begin{tabular}{|c|c|c|c|c|c|c|c|c|c|c|c|}
\hline \multicolumn{10}{|c|}{ Substrate metabolism* at two concentrations $(\% w / v)$} & \multirow[t]{3}{*}{ Biotype $†$} & \multirow{3}{*}{$\begin{array}{l}\% \text { Incidence among clinical } \\
\text { isolates }\end{array}$} \\
\hline \multicolumn{2}{|c|}{ Glycerol } & \multicolumn{2}{|c|}{ Inositol } & \multicolumn{2}{|c|}{ Lactose } & \multicolumn{2}{|c|}{ Glucose } & \multicolumn{2}{|c|}{ Xylose } & & \\
\hline 0.6 & 0.4 & $0 \cdot 3$ & 0.2 & 0.3 & $0 \cdot 2$ & 0.3 & 0.2 & $0 \cdot 3$ & 0.2 & & \\
\hline+ & + & - & - & - & - & - & - & + & - & 20001 & 4 \\
\hline+ & - & + & - & + & + & + & + & + & + & 11222 & 5 \\
\hline+ & - & + & - & + & - & + & - & + & + & 11112 & 7 \\
\hline+ & - & - & - & + & + & + & + & + & + & 10222 & 10 \\
\hline+ & - & + & - & + & - & + & - & + & - & 11111 & 11 \\
\hline+ & - & - & - & - & - & - & - & - & - & 10000 & 4 \\
\hline- & - & + & - & + & - & - & - & + & - & 01101 & 6 \\
\hline- & - & - & - & + & + & + & + & + & + & 00222 & 18 \\
\hline- & - & - & - & + & + & + & + & + & - & 00221 & 13 \\
\hline- & - & - & - & + & - & + & + & + & - & 00121 & 5 \\
\hline
\end{tabular}

* Substrate metabolism was recorded as positive $(+)$, indicator colour change in Andrade's peptone water with added substrate; negative ( - ), no indicator colour change; or weak $(w)$ in the presence of weak indicator colour change.

$\dagger$ Biotype was derived as described in Material and methods. Each digit of biotype refers to the metabolism of each substrate in order: glycerol, inositol, lactose, glucose, and xylose. In each case, a positive result at both concentrations of a substrate was recorded as ' 2 '; a positive result at the higher substrate concentration only as ' 1 '; and a negative result at both substrate concentrations as ' 0 '.

$11222 / 22222$ was identified which could be clearly and reproducibly distinguished from both 11222 and 22222 on repeated testing.

\section{Klebsiella biotypes}

In the series of 322 clinical isolates of klebsiella examined, 63 biotypes were distinguished. Of these, 32 biotypes were isolated on one or two occasions only; 31 biotypes accounted for $84 \%$ of the isolates. The 20 major biotypes are recorded (Table 2).

Of the dominant types, biotypes 11222,11111 , and 00222 were isolated throughout the period of this investigation from many different wards. Isolations of biotype 00112 were to a large degree restricted in distribution. Clusters of isolations of biotypes 11222 and 00112 suggested that the presence of a changing environmental reservoir or cross-infection may have contributed to their predominance in some wards.

\section{Enterobacter isolates}

Among 123 clinical isolates of E.aerogenes examined, 24 biotypes were distinguished. Ten biotypes accounted for $83 \%$ of the isolates (Table 3). As with klebsiella, enterobacter biotypes were distinguished that showed considerable variation in the metabolism of the substrates utilised. However, the percentage distribution of enterobacter biotypes was quite distinct from the distribution of biotypes among klebsiella strains (Tables 2 and 3 ).

\section{MULTIPLE BIOTYPES IN URINE: BIOTYPES IN} REPEAT SAMPLES

Of 80 urine sediments examined, seven catheter specimens yielded two or more types which were distinguished by differences in colonial form or medium indicator colour change. In all seven cases these differences were detected on MacConkey agar; in four cases two or more distinguishable types were also detected on one or more minimal media. In four of these cases, examination of repeat specimens of urine yielded the same multiple biotypes.

In four of seven specimens that yielded apparently mixed growths on culture media, observed differences were complemented by differences demonstrated in biochemical typing by either method. In three cases, observed differences on culture plates were not confirmed by either biotyping method.

One specimen yielded two biotypes that could not be distinguished on culture plates. The presence of two types was recognised by both biotyping methods after random selection of colonies for study.

In the majority of cases where klebsiellae were isolated from repeat specimens of urine from the same patient, they were of the same biotype. However, not infrequently and especially in catheterised patients, different biotypes were isolated from the same patient on successive occasions; these changes were often accompanied by increased or decreased antibiotic sensitivity, and by recognisable colonial changes. Barr (1978) and Rennie and Duncan (1974) have previously shown that changes in biotype could occur, especially in patients with tracheostomies, and the latter authors showed that biotype changes were often accompanied by changes in capsular serotype.

Klebsiellae have been shown to succeed many other Enterobacteriaceae in colonisation of the urinary tract of individual patients; in other cases, klebsiellae were replaced by other Gram-negative bacilli in the same patient. 
REPRODUCIBILITY OF METHOD: CONTROL STRAINS

Barr (1978) evaluated the reproducibility of the methods used in the discrimination among klebsiella isolates by differential substrate metabolism. When the same methods were applied in the biotyping of $E$. aerogenes, uniform results were obtained when clinical isolates were typed on four successive days.

Small variation in test results occasionally occurred when the preparation of fresh test substrates was required. This variation could arise from the inaccurate preparation of the test substrates in Andrade's peptone water or when the introduction of a different manufacturer's batch of Andrade's peptone water was needed. Such variations in substrate resulted in the recording of uniformly stronger or uniformly weaker test results, with either one or more substrates.

In order to detect any variation in biotype, eight control organisms were included in each batch of isolates examined. Control strains were carefully selected to show significant changes in biotype when small changes in substrate or environmental control occurred.

BIOCHEMICAL TYPING IN PRACTICAL USE

Several workers have shown that bowel carriage of klebsiellae may represent an important reservoir for hospital acquired infection by these organisms (Selden et al., 1971).

Bowel carriage may presumably be established inside or outside the hospital environment and may provide an endogenous source of infection. However, acquired bowel carriage may also contribute to environmental contamination, which may establish a source of infection for other patients. Skin carriage, which seems frequently to parallel bowel carriage, may also lead to cross-infection.

With these considerations in mind the following preliminary investigations were undertaken.

\section{Isolation of klebsiellae from faeces}

Faeces from 16 new staff members and 87 new admissions were examined. Klebsiellae were isolated from 57 specimens $(55 \%)$; these yielded 38 isolates of $K$. pneumoniae (sensu lato) and 21 isolates of $E$. aerogenes. From two specimens, two different klebsiellae were isolated.

Sixteen biotypes of klebsiella and 12 biotypes of enterobacter were identified (Table 4). The most common biotypes isolated from faeces were among those biotypes most commonly isolated from urine during the course of this investigation (cf, Tables 2 and 3 ).

Isolates of klebsiella and enterobacter were both relatively sensitive to antibiotics, 13 were sensitive to all antibiotics tested, 17 showed resistance to ampicillin only, and only nine showed multiple resistance (resistant to four or more antibiotics).

\section{Distribution of klebsiella biotypes in different wards}

Urine isolates of klebsiella were common from many wards. However, over any period, isolates of $E$. aerogenes were much less frequent and are not further discussed here although their potential importance in hospital acquired infection should not be understated.

The wards from which urine isolations of klebsiella were most common are shown in Table 5. In

Table 4 Major biotypes and antibiotic resistance of Klebsiella pneumoniae (sensu lato) and Enterobacter aerogenes isolated from faeces of staff and new admissions

\begin{tabular}{|c|c|c|c|c|c|c|}
\hline & \multirow[t]{2}{*}{ Biotypes } & \multirow[t]{2}{*}{ No. of isolates } & \multirow[t]{2}{*}{ No resistance } & \multicolumn{3}{|c|}{ Antibiotic resistance (No. of isolates with:) } \\
\hline & & & & $\begin{array}{l}\text { Ampicillin } \\
\text { resistance only }\end{array}$ & $\begin{array}{l}\text { Multiple* } \\
\text { resistance }\end{array}$ & $\begin{array}{l}\text { Othert } \\
\text { resistance }\end{array}$ \\
\hline \multicolumn{7}{|l|}{ Klebsiella pneumoniae } \\
\hline & 20222 & 5 & 3 & 1 & & 1 \\
\hline & $10222 / 20222$ & 4 & 2 & & 1 & 1 \\
\hline & 11222 & 4 & & 3 & & 1 \\
\hline & 01112 & 4 & & 2 & 1 & 1 \\
\hline & 00111 & 4 & & 2 & 1 & 1 \\
\hline & $\begin{array}{l}\text { Others ( } 11 \text { in } \\
\text { number) }\end{array}$ & 17 & 5 & 5 & 3 & 4 \\
\hline \multicolumn{7}{|l|}{ Enterobacter aerogenes } \\
\hline & 11222 & 2 & & & & 2 \\
\hline & 11111 & 2 & 1 & & & 1 \\
\hline & $\begin{array}{l}00222 / 10222 \\
\text { Others }(9 \text { in }\end{array}$ & 8 & 1 & 2 & 1 & 4 \\
\hline & number) & 9 & 1 & 4 & 1 & 3 \\
\hline
\end{tabular}

* Multiple resistance was arbitrarily defined as resistance to four or more antibiotics.

†Resistant to less than four antibiotics, excepting those resistant to ampicillin only. 
Table 5 Biotype and antibiotic resistance of Klebsiella pneumoniae (sensu lato) isolates from urine from different wards over a 12-month period (February 1978-January 1979)

\begin{tabular}{|c|c|c|c|c|c|c|c|c|}
\hline \multirow[t]{2}{*}{ Ward } & & \multirow{2}{*}{$\begin{array}{l}\text { No. of } \\
\text { isolates }\end{array}$} & \multicolumn{2}{|c|}{ Biotypes identified } & \multicolumn{4}{|c|}{ Antibiotic resistance (No. of isolates with:) } \\
\hline & & & Number & $\begin{array}{l}\text { Dominant types } \\
\text { (number of isolates) }\end{array}$ & $\begin{array}{l}\text { No } \\
\text { resistant }\end{array}$ & $\begin{array}{l}\text { Ampicillin } \\
\text { resistance only }\end{array}$ & $\begin{array}{l}\text { Multiple } \\
\text { resistance }\end{array}$ & $\begin{array}{l}\text { Other } \\
\text { resistance }\end{array}$ \\
\hline $\begin{array}{l}9 \\
19 / 20\end{array}$ & $\begin{array}{l}\text { General } \\
\text { medicine } \\
\text { General }\end{array}$ & 17 & 9 & $11222(4), 00111(4)$ & $\mathbf{0}$ & 4 & 13 & \\
\hline $\begin{array}{l}39 / 40 \\
41 / 42\end{array}$ & $\begin{array}{c}\text { surgery } \\
\text { Neurosurgery } \\
\text { Orthopaedics }\end{array}$ & $\begin{array}{l}20 \\
27 \\
72\end{array}$ & $\begin{array}{l}13 \\
10 \\
10\end{array}$ & $\begin{array}{l}- \\
00222(4), 11222(4) \\
11222(25), 00112(28)\end{array}$ & 1 & $\begin{array}{l}3 \\
4\end{array}$ & $\begin{array}{l}13 \\
22 \\
72\end{array}$ & $\begin{array}{l}3 \\
1\end{array}$ \\
\hline
\end{tabular}

most wards numerous biotypes were identified over a 12-month period; no preponderance of any one biotype was found in most wards during this period.

However, in two orthopaedic wards (41/42), klebsiella isolates accounted for a greater proportion $(31 \%)$ of bacteriurias than in other wards. The vast majority of isolates were derived from the female ward, ward 42 . Over the 12-month period, 72 isolates were ascribed to only 10 biotypes. Two biotypes, 11222 and 00112 , predominated; 28 isolations of biotype 00112 and 25 isolations of biotype 11222 were recorded. A longitudinal study showed that biotype 11222 predominated in the earlier months and was largely replaced as dominant biotype by 00112 in the latter period (Table 6).

Biotype 11222 is a common type (Table 2) which has been isolated from faeces of staff and new admissions (Table 4) and from urine in other wards (Table 5). However, the preponderance of this biotype, and biotype 00112 , at different periods in wards $41 / 42$ might be explained by cross-infection or the presence of a changing environmental reservoir. Further evidence for this was obtained by demonstrating the homogeneity of the populations of these biotypes by R-plasmid studies and capsular serotyping.

Nineteen isolates of biotype 11222 were examined for their ability to transfer antibiotic resistance to $E$. coli. From 14 donor isolates, $E$. coli acquired resistance to tetracycline, kanamycin, streptomycin, and ampicillin. Four isolates transferred resistance to ampicillin and streptomycin, and one isolate transferred resistance to ampicillin only.
Six isolates of biotype 11222, derived from wards 41/42 during April 1978, and 10 isolates of biotype 00112 , from the latter half of 1978 , were capsular serotyped by counter immunoelectrophoresis at our request by the Coventry Public Health Laboratory. Isolates of biotype 11222 uniformly typed as capsular serotype $\mathrm{K} 21$; isolates of biotype 00112 uniformly typed as capsular serotype $\mathrm{K} 43$.

An evaluation of antibiotic resistance of klebsiella isolates (Table 5) indicated that the vast majority of isolates from all wards showed multiple resistance, and did not suggest a special status for isolates from wards $41 / 42$ in this respect. However, isolates from wards 41/42 showed characteristically greater antibiotic resistance, demonstrated by uniform resistance to kanamycin and a proportionally greater resistance to tetracycline, cephalosporin, and naladixic acid. The majority of isolates of biotype 11222 were resistant to naladixic acid; isolates of biotype 00112 were uniformly sensitive.

\section{Discussion}

A biochemical typing method is described which allows considerable discrimination between clinical isolates of $K$. pneumoniae (sensu lato). Preliminary evidence suggests that the method may also be of value in defining biotypes of E. aerogenes. This is of particular value since conventional biotyping of Klebsiella spp (Rennie and Duncan, 1974), on its own, is insufficiently discriminating. Biotyping by differential substrate metabolism may be used to complement conventional biotyping. However, the

Table 6 Incidence of urine isolates of Klebsiella pneumoniae (sensu lato) biotypes from two orthopaedic wards (41/42) during a 12-month surveillance period

\begin{tabular}{|c|c|c|c|c|c|c|c|c|c|c|c|c|}
\hline & $\begin{array}{l}1978 \\
F e b\end{array}$ & Mar & $A p r$ & May & June & July & Aug & Sept & $O c t$ & Nov & Dec & $\begin{array}{l}1979 \\
\text { Jan }\end{array}$ \\
\hline $\begin{array}{l}\text { All klebsiella biotypes } \\
\text { Biotype } 11222 \\
\text { Biotype } 00112\end{array}$ & $\begin{array}{l}8 \\
7\end{array}$ & $\begin{array}{r}10 \\
4 \\
1\end{array}$ & $\begin{array}{l}9 \\
4\end{array}$ & $\begin{array}{l}5 \\
3\end{array}$ & $\begin{array}{l}3 \\
1 \\
2\end{array}$ & $\begin{array}{l}9 \\
3 \\
5\end{array}$ & $\begin{array}{l}2 \\
1 \\
1\end{array}$ & $\frac{5}{5}$ & $\frac{4}{4}$ & $\frac{2}{2}$ & $\begin{array}{l}2 \\
1 \\
1\end{array}$ & $\begin{array}{l}15 \\
1 \\
7\end{array}$ \\
\hline
\end{tabular}

NB Only the initial isolation of a klebsiella biotype from a patient is recorded. Where sequential colonisation by two klebsiella biotypes occurred the initial isolation of both is recorded. 
evidence presented suggests that sufficient discrimination may be obtained by the former method alone.

The reproducibility of the techniques employed has been evaluated (Barr, 1978). Repeat samples of urine from the same patient normally yielded the same biotype, and the method allowed the detection of occasional mixed biotypes in catheter specimens. This technique, by employing methods and materials normally available in bacteriology laboratories, could provide a rapid and convenient method for the screening of klebsiella isolates during routine surveillance.

However, variations between batches of Andrade's peptone water, the substrate base, and sensitivity to environmental variation may make comparison between laboratories difficult without careful standardisation. It may be convenient for laboratories to institute surveillance by the described biochemical methods and to determine the capsular serotype of 'epidemic strains' with the help of a reference laboratory, for purposes of communication.

Evidence, to be published later, has been obtained in this laboratory, which suggests that strain differences in the metabolism of the substrates used in the typing procedure may in part be mediated by plasmids. Reeve and Braithwaite (1973) have shown that strong and weak lactose fermenting phenotypes among klebsiella strains may result from the presence or absence of a plasmid which enhances $\beta$-galactosidase activity. Other workers (Cornelis et al., 1978) have shown that the introduction of plasmids may alter the ability of recipient strains to ferment certain substrates. This work is being pursued with a view to establishing the stability and potential transmissibility of plasmids which may influence the characters utilised here in discrimination between strains.

The technique allowed the recognition of many biotypes. Bowel carriage, which has been shown to provide a reservoir for the spread of klebsiellae (Selden et al., 1971), was common among new staff members and new admissions in general, and many biotypes were identified which were shown to be relatively antibiotic sensitive. However, in two orthopaedic wards $(41 / 42)$, where colonisation by klebsiella was most common, two multiply antibioticresistant biotypes predominated.

The predominance of two biotypes, at different periods, in wards $41 / 42$ suggested the possibility that cross-infection or an environmental reservoir was implicated. Representative isolates of biotype 11222 , which predominated in the first part of 1978 , were of the same capsular serotype, K21, and the majority of isolates carried the same $R$-factor. Representative isolates of biotype 00112 were of the same capsular serotype, $\mathrm{K} 43$, which is a rare type in the absence of an outbreak or cross-infection situation. These two types were in general further differentiated by a difference in sensitivity to naladixic acid. Similar patterns of changing predominance have been found by other workers (Casewell and Phillips, 1978; Riser et al., 1978). These outbreaks have usually been self-limiting and may reflect a changing environmental reservoir.

In wards $41 / 42$, patients were frequently elderly, debilitated, and often incontinent and confused; among these admissions many had indwelling catheters, often for long periods of their stay. Many patients were given antibiotic therapy either prophylactically (often Magnapen) or because of their general condition, and this has been shown to predispose to klebsiella colonisation (Montgomerie et al., 1970). Certainly many of these patients were resident in these wards for long periods, and by their predisposition, individual patients could have acted as reservoirs for the predominating biotypes. This may have contributed to cross-infection and the seeding of environmental sites by the means suggested by other workers as important vehicles of spread of klebsiella (Riser et al., 1978; Curie et al., 1978).

Certainly no change in ward policy or management occurred which could explain the change in preponderance, with time, of the two biotypes concerned. However, although no evidence for the origin of spread of the two predominating multiply resistant biotypes is offered, the data may reflect that three factors, viz, selective antibiotic pressure, heavily colonised patients, and catheterisation, may have compromised patients in these wards to urinary tract colonisation.

We thank Professor R. R. Gillies for constructive criticism of the paper and Mrs W. Booth for preparation of the text. We are grateful to Dr P. R. Mortimer, Coventry Public Health Laboratory, for serotyping selected klebsiella isolates by counter immunoelectrophoresis.

\section{References}

Barr, J. G. (1978). Variation in metabolism of biochemical test substrates by Klebsiella species: an epidemiological tool. Journal of Medical Microbiology, 11, $501-511$.

Barr, J. G., and Mahood, R. J. (1976). An assessment of inositol fermentation by Klebsiellae and its implication in screening media. Journal of Clinical Pathology, 29, 827-832.

Barr, J. G., Mahood, R. J., and Curry, K. P. W. (1977). Factors affecting the value of a simple biochemical scheme for identifying enterobacteriaceae: the reproducible recognition of biotypes. Journal of Clinical 
Pathology, 30, 495-504.

Casewell, M. W. (1972). Experiences in the use of commercial antisera for the capsular typing of Klebsiella species. Journal of Clinical Pathology, 25, 734-737.

Casewell, M. W., and Phillips, I. (1978). Epidemiological patterns of Klebsiella colonization and infection in an intensive care ward. Journal of Hygiene, 80, 295-300.

Cornelis, G., Luke, R. K. J., and Richmond, M. H. (1978). Fermentation of raffinose by lactose-fermenting strains of Yersinia enterocolitica and by sucrosefermenting strains of Escherichia coli. Journal of Clinical Microbiology, 7, 180-183.

Cowan, S. T. (Ed.) (1974). Cowan and Steel's Manual for the Identification of Medical Bacteria. 2nd edition. Cambridge University Press, London.

Curie, K., Speller, D. C. E., Simpson, R. A., Stephens, M., and Cooke, D. I. (1978). A hospital epidemic caused by a gentamicin-resistant Klebsiella aerogenes. Journal of Hygiene, 80, 115-123.

De Silva, M. I., and Rubin, S. J. (1977). Multiple biotypes of Klebsiella pneumoniae in single clinical specimens. Journal of Clinical Microbiology, 5, 62-65.

Heddell, G. W., and Mitchell, A. A. B. (1978). Evaluation and application of an improved bacteriocin typing method for Klebsiella aerogenes. Journal of Clinical Pathology, 31, 16-21.

Montgomerie, J. Z., Doak, P. B., Taylor, D. E. M., North, J. D. K., and Martin, W. J. (1970). Klebsiella in faecal flora of renal-transplant patients. Lancet, 2, 787-792.

Palfreyman, J. M. (1978). Klebsiella serotyping by counter- current immunoelectrophoresis. Journal of Hygiene, 81, 219-225.

Reeve, E. C. R., and Braithwaite, J. A. (1973). Lac+ plasmids are responsible for the strong lactosepositive phenotype found in many strains of Klebsiella species. Genetical Research, 22, 329-333.

Rennie, R. P., and Duncan, I. B. R. (1974). Combined biochemical and serological typing of clinical isolates of Klebsiella. Applied Microbiology, 28, 534-539.

Riser, E., Noone, P., and Poulton, T. A. (1976). A new serotyping method for Klebsiella species: development of the technique. Journal of Clinical Pathology, 29, 296-304.

Riser, E., Noone, P., and Thompson, R. F. M. (1978). The use of a fluorescence typing method in an epidemiological study of Klebsiella infection in a London hospital. Journal of Hygiene, 80, 43-56.

Selden, R., Lee, S., Wang, W. L. L., Bennett, J. V., and Eickhoff, T. C. (1971). Nosocomial Klebsiella infections: intestinal colonization as a reservoir. Annals of Internal Medicine, 74, 657-664.

Ślopek, S., and Maresz-Babczyszyn, J. (1967). A working scheme for typing Klebsiella bacilli by means of pneumocins. Archivum Immunologiae et Therapiae Experimentalis, 15, 525-529.

Requests for reprints to: Dr J. G. Barr, Department of Bacteriology, Royal Victoria Hospital, Belfast BT12 6BA, UK. 